\title{
Neurological manifestation on Leishmania siamensis: existed or not?
}

\section{Existem manifestações neurológicas na Leishmania siamensis?}

\section{Dear Editor,}

Leishmaniasis is an important insect borne infection that is endemic in South America, Africa and the Middle East. However, within the recent few years, the new infection due to Leishmania siamensis is observed in Southeast Asia ${ }^{1,2}$. This new species of Leishmania can cause both visceral and cutaneous forms of clinical manifestation. Focusing on neurological manifestation, Petersen and Greenlee reported that "there are multiple reported instances both in human and veterinary medicine where neurologic manifestations, whether central or peripheral 3". In fact, Llanos-Cuentas et al. mentioned that neurological manifestation of leishmaniasis is possible and can be forgotten ${ }^{4}$. Llanos-Cuentas et al. proposed that "in patients from Leishmania-endemic areas, when observing neurological symptoms, causation secondary to infection with Leishmania spp. may be considered ${ }^{4}$." Focusing on the new species infection from Thailand, there has never been information regarding neurological manifestation. Here, the authors tried to summarize the previous reports on this new infection. Of available reports on 8 cases of infection $^{1,2,5}$ there is no observed neurological manifestation. Further studies on the possibility of neurological involvement of Leishmania siamensis is the topic for further research.

Sora Yasri ${ }^{1}$, Viroj Wiwanitkit ${ }^{2,3}$

\section{References}

1. Bualert L, Charungkiattikul W, Thongsuksai P, Mungthin M, Siripattanapipong S, Khositnithikul R et al. Autochthonous disseminated dermal and visceral leishmaniasis in an AIDS patient, southern Thailand, caused by Leishmania siamensis. Am J Trop Med Hyg. 2012;86(5):821-4. http://dx.doi.org/10.4269/ajtmh.2012.11-0707

2. Osatakul S, Mungthin M, Siripattanapipong S, Hitakarun A, Kositnitikul R, Naaglor Tet al. Recurrences of visceral leishmaniasis caused by Leishmania siamensis after treatment with amphotericin B in a seronegative child. Am J Trop Med Hyg. 2014;90(1):40-2. http://dx.doi.org/10.4269/ajtmh.13-0398
3. Petersen CA, Greenlee MH. Neurologic manifestations of Leishmania spp: infection.J Neuroparasitology. 2011;2. pii: N110401.

4. Llanos-Cuentas A, Valencia BM, Petersen CA. Neurological manifestations of human leishmaniasis. Handb Clin Neurol. 2013;114:193-8. http://dx.doi.org/10.1016/B978-0-444-53490-3.00013-3

5. Suankratay C. Autochthonous Leishmaniasis: an emerging zoonosis in Thailand. J Infect Dis Antimicrob Agents. 2014;31(1):1-8.

${ }^{1}$ KMT Primary Care Center, Bangkok Thailand;

${ }^{2}$ Hainan Medical University, China;

${ }^{3}$ Joseph Ayobabalola University, Nigeri.

Correspondence: Sora Yasri; KMT Primary Care Center, Bangkok Thailand; E-mail: sorayasri@outlook.co.th

Conflict of interest: There is no conflict of interest to declare.

Received 31 October 2014; Received in final form 06 January 2015; Accepted 26 January 2015. 